\title{
ファジイハフ変換の勾配アルゴリズム
}

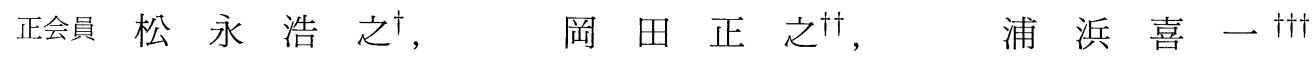

\section{Gradient Algorithms for Fuzzy Hough Transform}

\author{
Hiroyuki Matsunaga ${ }^{\dagger}$, Masayuki Okada ${ }^{\dagger \dagger}$ and Kiichi Urahama ${ }^{\dagger \dagger}$
}

\begin{abstract}
あらまし テンプレートマッチングを最適化問題として定式化して, 八フ変換のテンプレート マッチングやロバスト回帰との等価性を示す。また，ファジイハフ変換に打けるメンバーシップ関 数をこの定式化から導出し, データ点とテンプレートとの距離が解杤的には表せない場合の勾配法 によるファジイハフ変換アルゴリズムを導く.
\end{abstract}

\section{1. ま え がき}

ハフ変換がテンプレートマッチングと等価であるこ とは周知である ${ }^{1)}$.また別の観点として，八フ変換が ロバスト回帰の 1 種とも見れることも知られている ${ }^{2)}$. 本報告ではテンプレートマッチングの最適化問題とし ての定式化に基づいて，これらの等価性を統一的に導 く.また，これまで経験的に設定されていたファジイ ハフ変換 ${ }^{3)}$ のメンバーシップ関数をこの定式化から導 く. ファジイハフ変換のこの最適化問題による定式化 のひとつの応用例として, テンプレートが高次の関数 で表される場合のように，データ点とテンプレートと の距離が解析的には表せない場合の勾配法によるファ ジイハフ変換アルゴリズムを導いて, 簡単な実験によ りこのアルゴリズムの有効性を検証する.

\section{2. 可変型テンプレートマッチング}

データとして $m$ 個の点 $d_{i}(i=1, \ldots, m)$ が与 えられるとする。この点パターンから $n$ 個のテン プレートを抽出する。テンプレートのパラメータを $p_{j}(j=1, \ldots, n)$ とする. 例えばテンプレートが直線 $y=a x+b$ である場合には $p_{j}=\left(a_{j}, b_{j}\right)$ である. 点 $d_{i}$ と第 $j$ テンプレートとの距離を $D\left(d_{i}, p_{j}\right)$ と記す. このように定義するとテンプレートマッチングは

$$
\begin{aligned}
\min & \sum_{i=1}^{m} \sum_{j=1}^{n} x_{i j} D\left(d_{i}, p_{j}\right) \\
\text { subj.to } & \sum_{j=1}^{n} x_{i j}=1(i=1, \ldots, m) \\
& x_{i j} \in\{0,1\}
\end{aligned}
$$

という混合整数計画問題として定式化される.バイナ リ変数 $x_{i j}$ は点 $d_{i}$ が第 $j$ テンプレートに属すメン バーシップを表す. (1) 式で最適化すべき変数は $x_{i j}$ と $p_{j}$ である. (1) 式は可変形 (deformable) テンプレー トマッチングと呼ばれ, 近似最適解を求めるニューラ ルネットアルゴリズムが提案されている4). 似た解法 として, ホップフィールドネットワークによる方法も 試みられている5)。しかし（1）式では各 $d_{i}$ は必ずど れか 1 つのテンプレートに属すことになるので, テン

キーワード：ハフ変換, ファジイハフ変換, テンプレートマッチング, ロバスト回帰 1996 年 5 月 7 日受付, 1996 年 5 月 31 日再受付

†株式会社富士通九州システムエンジニアリング（テ 814 福岡市早良区百道浜 2-2-1, TEL 092-852-3130)

†北九州職業能力開発短期大学校 情報技術科（广 803 北九州市小倉南区志井 1665-1, TEL 093-963-0125）

†† 九州芸術工科大学 画像設計学科 ( $\bar{T} 815$ 福岡市南区塩原 4-9-1, TEL 092-553-4510)

$\dagger$ Fujitsu Kyushu System Engineering (2-2-1, Momotihama, Sawara-ku, Fukuoka-shi, Fukuoka 812, Japan)

†† Kitakyushu Polytechic Callege (1665-1, Shii, Kokuraminami-ku, Kitakyushu-shi, Fukuoka 803, Japan)

$\dagger \dagger \dagger$ Kyushu Institute of Design (4-9-1, Siobaru, Mianmi-ku, Fukuoka-shi, Fukuoka 815, Japan) 
プレートから大きく外れたノイズデータがあると抽出 されるテンプレートが正しい位置からずれてしまう. この問題点を解消して外れデータ (outliers) に対し てロバストにするには（1）式を

$$
\begin{aligned}
\min & \sum_{i=1}^{m} \sum_{j=1}^{n} x_{i j} D\left(d_{i}, p_{j}\right)+\alpha \sum_{i=1}^{m} x_{i, n+1} \\
\text { subj.to } & \sum_{j=1}^{n+1} x_{i j}=1(i=1, \ldots, m) \\
& x_{i j} \in\{0,1\}
\end{aligned}
$$

と変更すればよい。こうすれば，どのテンプレート からも距離 $\alpha$ 以上離れているような外れデー夕では $x_{i j}=0(j=1, \ldots, n), x_{i, n+1}=1$ となり，そのよう な外れデー夕は無視される。同様なロバスト化はクラ スタリングでも使われており ${ }^{6)}$,(2) 式はその一般化に なっている（テンプレートが代表点である場合が通常 のクラスタリングである) .

この方法では抽出するテンプレートの数 $n$ をあらか じめ設定しなければならないが，この設定は一般には 困難である。そこでいっそのこと $n=1$ としてみる. すなわちテンプレート図形を 1 個抽出する場合を考え る。すると（2）式は

$$
\begin{gathered}
\min \sum_{i=1}^{m} x_{i} D\left(d_{i}, p\right)+\alpha \sum_{i=1}^{m}\left(1-x_{i}\right) \\
x_{i j} \in\{0,1\}
\end{gathered}
$$

となり, 定数項は取り除いてよいので結局

$$
\begin{gathered}
\min \sum_{i=1}^{m}\left[D\left(d_{i}, p\right)-\alpha\right] x_{i} \\
x_{i j} \in\{0,1\}
\end{gathered}
$$

となる.（3）式はマルコフランダム場による画像復元 で使われるラインプロセスと同じ形の式であり，この 形の最適化問題がロバスト推定の一種である $\mathrm{M}$ 推定 と等価であることが知られている ${ }^{7)}$. (4) 式の解 $x_{i}$ は

$$
x_{i}= \begin{cases}1 & D\left(d_{i}, p\right) \leqq \alpha \\ 0 & D\left(d_{i}, p\right)>\alpha\end{cases}
$$

となる．距離 $D\left(d_{i}, p\right)$ の取り方にはいろいろあるが, 特殊な場合として

$$
D\left(d_{i}, p\right)= \begin{cases}0 & D_{E}\left(d_{i}, p\right) \leqq \alpha \\ D_{E}\left(d_{i}, p\right) & D_{E}\left(d_{i}, p\right)>\alpha\end{cases}
$$

というのを考える.ここで $D_{E}\left(d_{i}, p\right)$ は $d_{i}$ とテンプ レートとのユークリッド距離である. $D\left(d_{i}, p\right)$ がこの
ような距離であるときには（4）式は

$$
\min -\alpha \sum_{i=1}^{m} x_{i}
$$

すなわち

$$
\max \sum_{i=1}^{m} x_{i}
$$

となり, (5) 式は

$$
x_{i}= \begin{cases}1 & D_{E}\left(d_{i}, p\right) \leqq \alpha \\ 0 & D_{E}\left(d_{i}, p\right)>\alpha\end{cases}
$$

となる。すなわちパラメータ $p$ の空間で (9) 式に従つ て $x_{i}$ を算出すれば, その累積值 $\Sigma x_{i}$ が最大になる $p$ がテンプレートの位置を与えることになる。これはロ バストハフ変換法の一種である ${ }^{8)} . \alpha \downarrow 0$ の極限が狭 い意味のハフ変換すなわちラドン変換になる ${ }^{9)}$.

以上により, 八フ変換がテンプレートマッチングや ロバスト回帰と等価であることが最適化問題による定 式化から導かれた。なお，テンプレートにマッチする パターンが複数個あるときには，それぞれに対応する $p$ で $\Sigma x_{i}$ が極大になるから, 以上の方法で複数個のテ ンプレートパターンを抽出できる。これはロバスト回 帰の性質すなわち各パターンにとって他のパターンは すべて外れデータになることによる。

\section{3. ファジイハフ変換}

以上の方法すなわちハフ変換は $x_{i}$ が 0 か 1 の整 数值であるのでディジタルアルゴリズムであり, コン ピュータで効率的に実行できるが，テンプレートのパ ラメータの数が増えると計算量が増加し, また量子化 誤差などの問題がある ${ }^{10)}$. このような問題に対処する 1 方法としてファジイハフ変換が提案されている ${ }^{3)}$. 前 節のテンプレートマッチング法をファジイ化するには $x_{i}$ が取る值を実数値 $[0,1]$ として（4）式を

$$
\begin{aligned}
\min & \sum_{i=1}^{m}\left[D\left(d_{i}, p\right)-\alpha\right] x_{i}+\sum_{i=1}^{m} \phi\left(x_{i}\right) \\
& 0 \leqq x_{i} \leqq 1
\end{aligned}
$$

とする.関数 $\phi\left(x_{i}\right)$ に対する条件について考える. (10) 式の解 $x_{i}$ は

$$
D\left(d_{i}, p\right)-\alpha+\frac{d \phi}{d x_{i}}=0
$$

を満たす。これから $D\left(d_{i}, p\right)-\alpha=-d \phi / d x_{i}$ となる からこれを（10）式に代入すると（10）式は 


$$
\min \sum_{i=1}^{m}\left[\phi\left(x_{i}\right)-x_{i} \frac{d \phi}{d x_{i}}\right]
$$

となる.したがって $k$ をある正定数として $\phi\left(x_{i}\right)$ が

$$
\phi\left(x_{i}\right)-x_{i} \frac{d \phi}{d x_{i}}=-k x_{i}
$$

を満たせば（10）式は（8）式すなわちハフ変換と同じ になる．ただしこの場合 $x_{i}$ は実数值を取るのでファ ジイハフ変換になる。逆に $(10)$ 式がハフ変換をファ ジイ化したものになるためには $\phi\left(x_{i}\right)$ は（13）式を満 たさなければならない.(13) 式の解は

$$
\phi\left(x_{i}\right)=k x_{i}\left(\ln x_{i}-1\right)
$$

となる。 $\phi\left(x_{i}\right)$ が (14) 式のとき（10）式の解 $x_{i}$ は (11) 式から

$$
x_{i}=e^{\frac{\alpha-D\left(d_{i}, p\right)}{k}}
$$

となり，特に $\alpha \downarrow 0$ のとき $x_{i}=\exp \left(-D\left(d_{i}, p\right) / k\right)$ と なり,これを（8）式に代入するとファジイハフ変換は

$$
\max \sum_{i=1}^{m} e^{\frac{-D\left(d_{i}, p\right)}{k}}
$$

となる。これはすでに提案されているファジイハフ変 換の式のひとつに一致する ${ }^{3)}$. ファジイハフ変換のメ ンバーシップ関数 $e^{-D\left(d_{i}, p\right) / k}$ は従来経験的に設定さ れていたが, ここでの導出によりひとつの理論的な根 拠が与えられたことになる。すなわち（10）式はファ ジイハフ変換の原型となる式であり, ファジイハフ変 換の理論的基礎だけでなく, より一般的な状況やアル ゴリズムを扱うときの基本式となる，そのような応 用の一例として，テンプレートが直線や円といった簡 単なものでなく高次の関数で表される場合のように， データ点とテンプレートとの距離が解析的には表せ ないような場合に対する近似解法を導く.テンプレー トの式が $f(e, p)=0$ であるとする. $e$ は空間座標で あり, $p$ はパラメータである. 例えば 2 次元空間内 の直線のときには $e=\left(e_{x}, e_{y}\right), p=(a, b, c)$ として $f(e, p)=a e_{x}+b e_{y}+c$ である.このときテンプレー トマッチングは（10）式の一般形として

$$
\begin{aligned}
\min & \sum_{i=1}^{m} x_{i}\left\|d_{i}-e_{i}\right\|^{2}+k \sum_{i=1}^{m} x_{i}\left(\ln x_{i}-1\right) \\
\text { subj.to } & f\left(e_{i}, p\right)=0(i=1, \ldots, m) \\
& 0 \leqq x_{i} \leqq 1
\end{aligned}
$$

と表せる.ただし $\alpha$ は 0 とした。(17) 式で最適化すべ
き変数は $e_{i}, x_{i}$ および $p$ である. (17) 式から直ちに 分かるように $e_{i}$ の最適解は $d_{i}$ に最も近いテンプレー ト上の点となる.(17) 式の解はラグランジュ関数

$$
\begin{aligned}
L & =\sum_{i=1}^{m} x_{i}\left\|d_{i}-e_{i}\right\|^{2}+k \sum_{i=1}^{m} x_{i}\left(\ln x_{i}-1\right) \\
& +\sum_{i=1}^{m} \lambda_{i} f\left(e_{i}, p\right)
\end{aligned}
$$

の鞍点, すなわち

$$
\begin{aligned}
\frac{\partial L}{\partial x_{i}} & =\left\|d_{i}-e_{i}\right\|^{2}+k \ln x_{i}=0 \\
\frac{\partial L}{\partial e_{i}} & =2 x_{i}\left(e_{i}-d_{i}\right)+\lambda_{i} \frac{\partial f}{\partial e_{i}}\left(e_{i}, p\right)=0 \\
\frac{\partial L}{\partial \lambda_{i}} & =d\left(e_{i}, p\right)=0 \\
\frac{\partial L}{\partial p} & =\sum_{i=1}^{m} \lambda_{i} \frac{\partial f}{\partial p}\left(e_{i}, p\right)=0
\end{aligned}
$$

の解である.この 4 つの式を連立させて解けば解が得 られるが, 変数の数が多いので $p$ 以外の変数を消去し よう。そのために (20) 式を

$$
2 x_{i}\left(e_{i}-d_{i}\right)+\lambda_{i} \frac{\partial f}{\partial e_{i}}\left(d_{i}, p\right)=0
$$

と近似する。次に (21) 式をテーラー展開すると

$$
f\left(d_{i}, p\right)+\left(e_{i}-d_{i}\right)^{T} \frac{\partial f}{\partial e_{i}}\left(d_{i}, p\right)=0
$$

となる.(23) 式に $\partial f / \partial e_{i}\left(d_{i}, p\right)$ をかけると

$$
2 x_{i}\left(e_{i}-d_{i}\right)^{T} \frac{\partial f}{\partial e_{i}}\left(d_{i}, p\right)+\lambda_{i}\left\|\frac{\partial f}{\partial e_{i}}\left(d_{i}, p\right)\right\|^{2}=0
$$

となる.(24) 式と（25）式とから $\lambda_{i}$ が

$$
\lambda_{i}=\frac{2 x_{i} f\left(d_{i}, p\right)}{\left\|\frac{\partial f}{\partial e_{i}}\left(d_{i}, p\right)\right\|^{2}}
$$

と得られる。(26) 式を（23）式に代入して $e_{i}-d_{i}$ を 求めて, そのノルムをとると

$$
\left\|e_{i}-d_{i}\right\|^{2}=\frac{f^{2}\left(d_{i}, p\right)}{\left\|\frac{\partial f}{\partial e_{i}}\left(d_{i}, p\right)\right\|^{2}}
$$

となる. 次に（19）式から

$$
x_{i}=e^{\frac{-\left\|e_{i}-d_{i}\right\|^{2}}{k}}
$$

となり，これに（27）式を代入したものを（26）式に 代入し，さらにその（26）式を（22）式に代入すると (22) 式は

$$
\sum_{i=1}^{m} \frac{f\left(d_{i}, p\right) \frac{\partial f}{\partial p}\left(d_{i}, p\right)}{\left\|\frac{\partial f}{\partial e_{i}}\left(d_{i}, p\right)\right\|^{2}} e^{\frac{-f^{2}\left(d_{i}, p\right)}{k\left\|\frac{\partial f}{\partial e_{i}}\left(d_{i}, p\right)\right\|^{2}}}=0
$$



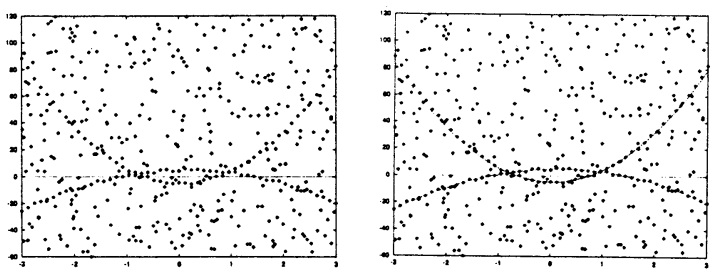

図 1 デー夕例

Example of data.

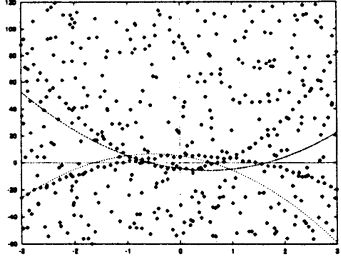

(a) $k=0.001$

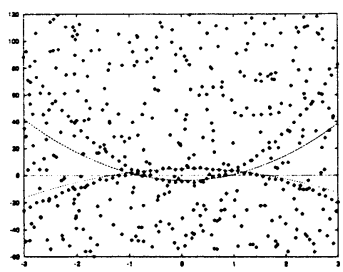

(b) $k=10.0$
図 2 不適切な $k$ の值での結果

Parabolas extracted with inappropriate values of $k$.

となり $p$ だけに関する式となる。これの解は勾配法

$$
\frac{d p}{d t}=-\frac{\partial L}{\partial p}
$$

で求まる $(\partial L / \partial p$ は $(29)$ 式の左辺である)。すなわ ち $p$ の適当な初期值から出発して (30) 式の軌道が収 束した值として 1 つの解が得られる。このとき解は一 般に複数個あるから初期值に最も近い解に収束する.

例題として図 1 左のような点パターンから放物線

$$
f(e, p)=a e_{x}+b e_{x}^{2}+e_{y}+c=0
$$

を抽出してみた。いろいろな初期值から出発して (30) 式をシミュレーションしてみたところ，どのような初 期值から出発しても図 1 右に示す 2 つの放物線のどち らかに収束した， $k$ の值は 0.1 とした， $k$ の值は適当 な範囲内になければならない。 小さすぎると局所最適 解につかまり，図 $2(\mathrm{a})$ のように正解に行かず，逆に大 きすぎるとノイズデータの影響を受けるようになり， やはり図 2 (b) のように正解からずれる.

\section{4. む す び}

ハフ変換を混合整数計画問題によって定式化した。 この定式化は，各デー夕点がテンプレートに属す割合 を表す局所的な变数 $x_{i}$ とテンプレートの大局的な布 置を表すパラメータ $p$ との互いの相互作用を記述して いる．すなわち $p$ が与えられれば $x_{i}$ は各デー夕点で 個別に計算され， $x_{i}$ がすべて与えられればその累積に
よって $p$ が決まる。このような $x_{i}$ と $p$ の逐次更新に よる解法は EM アルゴリズム ${ }^{11)}$ の一種であり, ハフ変 換と統計論との接点ともなる。また, 最適化問題の目 的関数にエントロピーに似た関数を付け加えることに よりファジイハフ変換が得られることも示した。この 付加関数の係数 $k$ を固定したものがファジイハフ変換 であるが，適当に大きな值から $k$ を徐々に減少させな がら解を追跡すればハフ変換の大域最適解を得ること ができる。これはニューラルネットによる最適化で用 いられる決定論的アニーリング12) と同じ手法であり， 非凸な最適化問題であるハフ変換の大域近似解法とな る.ここで導出したファジイハフ変換の勾配解法は, テンプレートのパラメータ数が多い場合に全空間探索 のハフ変換に代わる解法として, あるいはまず最初に 粗い分割のハフ変換で近似值を求めた後, 本勾配法で 精度を高めるといった使用法などが考えられる。いろ いろな画像で本方法の実用性を検証するのが今後の課 題である.

\section{〔参 考 文 献〕}

1) G.C. Stockman and A.K. Agrawala: "Equivalence of Hough curve detection to template matching", Comm. ACM, 20, pp.820-822 (1977)

2) G. Roth and M.D. Levine: "Extracting geometric primitives”, CVGIP: Image Understanding, 58, pp.1-22 (1993)

3) J.H. Han, L.T. Koczy and T. Poston: "Fuzzy Hough transform", Patt. Recog. Lett., 15, pp649-658 (1994)

4) M. Ohlsson, C. Peterson and A.L. Yuille: "Track finding with deformable templates-the elastic arms approach", Comput. Phys. Comm., pp.77-98 (1992)

5) B. Kamgar-Parsi and B. Kamgar-Parsi: "Simultaneous fitting of several planes to point sets using neural networks", Comput, Vision Graph. Image Process., 52, pp.341-359 (1990)

6) K. Urahama and Y. Furukawa: "Gradient descent learning of nearest neighbor classifiers with outlier rejection", Patt. Recog., 28, pp.761-768 (1995)

7) S.Z. Li: "Markov Random Field Modeling in Computer Vision", Springer-Verlag (1995)

8) S.D. Shapiro: "Generalization of the Hough transform for curve detection in noisy digital images", 4th IJCPR, pp.710-714 (1978)

9) S.R. Deans: "Hough transform from the Radon transform", IEEE Trans. Patt. Anal. Mach. Intell., PAMI-3, pp.185-188 (1981)

10) J. Illingworth and J. Kittler: "A survey of the Hough transform”, Comput. Vision Graph. Image Process., 44, pp.87-116 (1988)

11) A.L. Yuille, P. Stolorz and J. Utans: "Statistical physics, mixtures of distributions, and the EM algorithm", Neural Comp., 6, pp.334-340 (1994)

12) K. Urahama: "Analog method for solving combinatorial optimization problems”, IEICE Trans. Fund., E77-A, pp.302-308 (1994) 


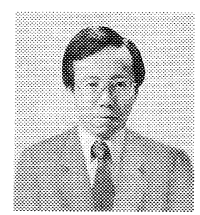

松永浩之 1985 年, 九州芸工大学芸術 工学部画像設計卒業. 1987 年, 同大大学院修 士課程修了。同年, (株) 富士通九州システム エンジニアリング入社. 1995 年, 九州芸工 大大学院博士課程在学中. ニューラルネット, 画像処理を研究. 正会員.

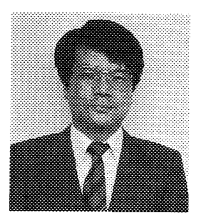

浦浜喜— 1976 年, 九州大学工学部電 子工学科卒業. 1981 年, 同大学大学院博士課 程修了. 同年同大学情報助手. 1989 年, 九州 工業大学情報工学部電子情報助教授. 1995 年, 九州芸術工科大学画像設計学科教授.二ュー ラルネット, 画像処理を研究.

岡田正之 1981 年, 東海大学工学部光 学工学科卒業. 1987 年, 雇用促進事業団入 団. 1996 年, 九州芸工大研究生. 画像処理老 研究. 